\title{
Child Abuse and Dental Practice: Finding the Nexus
}

\author{
Induwara Gooneratne* \\ Department of Forensic Medicine, University of Peradeniya, Sri Lanka
}

Received: December 18, 2017; Published: December 21, 2017

*Corresponding author: : Induwara Gooneratne, Department of Forensic Medicine, Faculty of Medicine, University of Peradeniya, Sri Lanka

\section{Introduction}

Many reports indicate that children are abused everyday worldwide. They are abused in many different ways [1]. Literature suggests that the numbers of reported abuses against children are a mere tip of an iceberg accordingly, there are many unreported cases - some are hidden or covered. Thus, child abuse becomes a social problem. Many seem to ignore child abuses, others of course will justify. Admittedly there are a few who will hide such abuses under a carpet or give a blind eye. In some societies child abuse has become a part of an accepted cultural practice- for example corporal punishments or female genital mutilations. Fortunately, there are some of us in the society who will voice against abuse of children. The social responses to child abuse are reflected in clinical sets up in similar ways. This means that some clinicians will ignore abuses while others may not care. The problem becomes aggravated in clinical scenarios especially when the clinician is not trained in identifying an imminent child abuse. In this context, this paper seeks to find a connection between clinical dental practice and child abuse. In short, I will argue and demonstrate in this paper that the presentations of cases of child abuse are not uncommon to the dental clinician, but that they are often times presented with alternate histories so that they can be easily missed by the clinician, if not looked through forensic lenses.

\section{Contextualising Child Abuse}

According to international law, especially based on the United Nations Convention of the Right of the Child (UNCRC), any person below the age of eighteen years is considered as a child. In this sense any violence or abuse against a person below eighteen years can be considered as child abuse. While child abuse can be presented in different forms, including physical, sexual, emotional or neglect forms, the perpetrator is usually a family member, care giver, custodian or a neighbour or at least a relative. Despite the fact that child abuse is frequently seen as an ongoing event with multiple chronological encounters, it can certainly happen as a single event. Further, child abuse can result from an action by the perpetrator or by inaction, for example not giving food or care. Given the serious impact it has on the child in his physical and psychological development, abuse and violence against children should be identified early to avoid further harm.

\section{Connecting the Dental Clinician}

While injuries to teeth and face are common among children, according to research, considerably a large number of them are due to abuse and violence [2]. Owing to their obvious appearance, swelling, bleeding and pain, usually the child will be presented to the dental clinician, of course with a misleading history. Those that are not presented to the clinician by parents or care givers, outsiders may notice injuries and may proceed to enquire - for example school teachers or neighbours. It is essential that the dental surgeon conduct an intra oral and peri oral examination carefully with a forensic eye in dealing with a suspected case of child abuse. Apart from the history from the guardian, a private interview with the child in the clinical set up may reveal some important information. The possibility of child abuse as a differential diagnosis has to be considered while attending to a child with a history of fall or accident, especially when the child is brought repeatedly. In the event where the clinician reasonably suspects child abuse, the case should be reported for medico-legal management-which is a legal requirement under almost all jurisdictions.

\section{Presentations of Abuses}

There have been instances of inflicting oral injuries with feeding instruments, for example using feeding bottles perhaps due to forced feeding. Further, fractures of teeth, contusions in and around the mouth and face, abrasions especially by finger nails or another object, fractures of mandible or maxilla due to violent assault, finger tip contusions around the mouth , burnt marks in and around the mouth especially with cigarettes, firewood or heated electric instruments, scalding resulted with hot water or liquids are common. The lips, teeth, buccal mucosa tongue and facial bones, gingival, alveolar bone are the commonest anatomical sites that are reported to have been affected [3]. Despite oral sex is a common type of sexual abuse among children, more often than not the child may not show physical features. However, it is possible that contusions occur inside the oral cavity mucosa or in and around the mouth due to refusal by the child and the concomitant force by the assailant. The confirmation of oral or peri-oral gonorrhoea or lesions associated with HIV for example oral candidacies are highly likely to be associated with child sexual abuse. 
Another frequent presentation will be bite marks [4]. While it can be alleged that the bites were made by peers or siblings, or as self inflicted, a careful forensic investigation may reveal whether or not the bites were made by an adult. In these scenarios it is important to distinguish a human bite mark from that of an animal origin and then from a peer child or an adult. A swab taken from the site for DNA and a careful forensic bite mark investigation can reveal the perpetrator. However, taking photographs, taking a swab for DNA and then timely attending to the analysis is important in this regard for administering justice. Dental neglect is another common occurrence. According to American Academy of Paediatric Dentistry, 'dental neglect is wilful failure of parent or guardian to seek and follow through with treatment necessary to ensure a level of oral health essential for adequate function and freedom from pain and discomfort'. If oral diseases of the child are left untreated without taking the child to a suitable clinician, then it can constitute dental neglect. In countries like Sri Lanka where all dental and medical health care is free for people, the responsibility of the guardian to seek dental health care rises. On the contrary, if the dental clinicians attending to children, neglect them either by not treating or not preventing dental diseases among the children they treat, that too can constitute dental neglect. With authors experience in a forensic set up, the commonest presentations of child abuse in Sri Lanka are contusions intra and peri oral, then fracture, dislocation or exfoliation of teeth. Author has reported mandibular fractures and fractures in teeth in chronic physical child abuse cases [5]. Further, corporal punishments especially by school teachers and parents where assault to face lead to dental injuries are common in Sri Lanka due to the cultural acceptance of physical child control.

\section{Conclusion}

Child abuse is prevalent in any society and the dental clinician should be aware and vigilant in managing children with suspected dental or oral presentations. Given the focus is more on the clinical management of the condition, a busy dental clinician can easily missing a child abuse being detected especially when the history given by the parents or guardian is misleading. Further, if the patterns of injuries are inconsistent with the history provided or there is evidence of repeated oral and dental injuries with multiple time intervals, it is highly likely that the child is being abused. In such a suspicious situation, it is the responsibility of the dental clinician to initiate a medico-legal management involving the authorities.

\section{References}

1. Kellog,N (2005) Oral and Dental Aspects of Child Abuse and Neglect. Pediatrics 116(6): 1565-1568.

2. Becker DB, Needleman HL, Kotelchuk M (1978) Child Abuse and Dentistry: Orofacial trauma and its Recognition by Dentists. J Am Dent Assoc 97(1): 24-28.

3. Jessee SA (1995) Physical Menefestations of Child Abuse to the head, face and mouth : A Hospital Survey. ASDC J Dent Child 62(4): 245-249.

4. Needleman HL (1986) Orofacial trauma in Child Abuse: Types, Prevelence,Management, and the dental practitioners involvement. Pediatr Dent 8: 71-80.

5. Gooneratne I (2003) Child Abuse-a Case Report in Sri Lanka. Sri Lanka Dental Association Regional Sessions Proceedings 20.

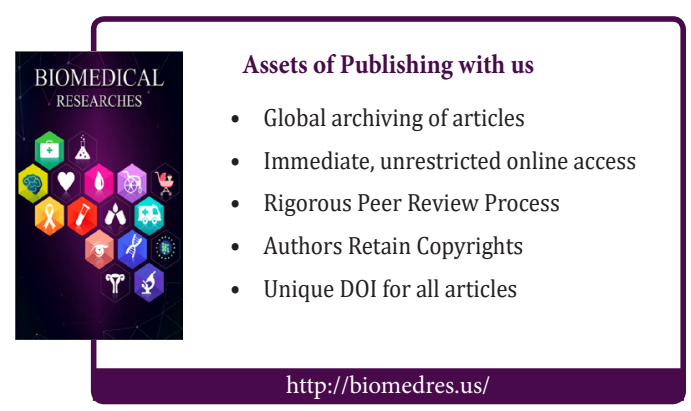

